Introduction Renal connective tissue, characterised by the presence of loose ligaments throughout the body. This condition affects the joints throughout the body and is a generalised hypermobility, occurs in about $5 \%$ of the population and can be genetically conditioned.

Objective To examine the incidence of renal connective tissue and their representation by age and sex, the applied treatment and the need for hospitalisation.

Methods and materials Our target group were patients aged 1014 years, who are treated in the Department of Children Health Care, Health Centre Novi Sad in period (2011 to 2013), And used data from the Health patient records, on which was conducted retrospective-prospective study.

Results After examining the medical records, we came up with the following data: 463 (59.28\%) males and 764 (62.31) females, in which it was manifested weak connective tissue with various spectrum disorders and distinctive bluish whites.

Conclusion Poor connective tissue occurs before puberty and causes a wide spectrum of disorders: vision problems, curve the spine, frequent injuries of joints, constipation, prolapse of heart valves and other. There a way to cure, but rather to alleviate symptoms and to slow its progression, there are numerous events which may be unpleasant, and even that complicated.

\section{PO-0081 PITUITARY STALK INTERRUPTION SYNDROME: CLINICAL, RADIOLOGIC AND THERAPEUTIC PARTICULARITY}

${ }^{1} \mathrm{M}$ Tfifha, ${ }^{1} \mathrm{D}$ Dhahri, ${ }^{1} \mathrm{H}$ Ajmi, ${ }^{2} \mathrm{~K}$ Kadri, ${ }^{1} \mathrm{~S}$ Mabrouk, ${ }^{1} \mathrm{~J}$ Chemli, ${ }^{1} \mathrm{~N}$ Zouari, ${ }^{1} \mathrm{~S}$ Hassayoun, ${ }^{2} \mathrm{~K}$ Tlili, ${ }^{1} \mathrm{~S}$ Abroug. ${ }^{1}$ Pediatrics, University Hospital Sahloul, Sousse, Tunisia; ${ }^{2}$ Radiology, University Hospital Sahloul, Sousse, Tunisia

10.1136/archdischild-2014-307384.751

Background Patients with congenital hypopituitarism might have the classic triad of pituitary stalk interruption syndrome (PSIS), which consists of: an interrupted or thin pituitarys talk, an absent or ectopic posterior pituitary (EPP), and anterior pituitary hypoplasia or aplasia. The most remarkable clinical manifestations of patients with PSIS was growth retardation.

Objective To analyse the clinical, auxological and radiologic characteristics of the patients with PSIS to achieve better comprehension of this pathology.

Methods Data of patients with PSIS were retrospectively analysed for the clinical, laboratory and imaging features.

Results Five patients were included ( 4 girls and 1 boy). They are aged at the first clinical manifestation from 1 month to 3 years. The symptoms that led to the diagnosis were failure to thrive in four cases and polyuria-polydipsia syndrome in one case.

A complete growth hormone deficiency was confirmed in four cases, one was complicated with central hypothyroidism and one was accompanied by central adrenocortical hypofunction.

The last patient present only central diabetes insipidus.

Hypothalamo-pituitary MRI was performed in all of the patients showed one or more elements of the classic triad.

A causative mutation was studied in two patients. None HESX1 or LHX4 mutations was found.

Conclusion The PSIS is relatively frequent. The outcome is progressive evolution towards panhypopituitarism. The treatment consists in hormone replacement therapy.

\section{PO-0082 ELEVATED BLOOD PRESSURE IN EMIRATI ADOLESCENTS: ROLE OF OBESITY?}

${ }^{1} \mathrm{~S}$ Al Tandi, ${ }^{1} \mathrm{M}$ Al Aghbari, ${ }^{1} \mathrm{~N}$ Al Zaabi, ${ }^{1} \mathrm{~A}$ Al Marzoogie, ${ }^{1} \mathrm{~S}$ Al Hadraami, ${ }^{2} \mathrm{~S}$ Shah. ${ }^{1}$ Medical Student, College of Medicine and Health Sciences- United Arab Emirates University, Al-Ain, United Arab Emirates; ${ }^{2}$ Institute of Public Health, College of Medicine and Health Sciences- United Arab Emirates University, Al-Ain, United Arab Emirates

\subsection{6/archdischild-2014-307384.752}

Objectives Although obesity is fast increasing, there are few data on the prevalence of high-normal or elevated blood pressure in United Arab Emirates.

Methods We conducted a school-based survey of a representative sample of youth $(\mathrm{n}=1524)$ aged 12 to 18 years in Al Ain, UAE. BP measurements were made with a manual sphygmomanometer by trained nurses. Additional measures included height, weight, and abdominal circumference. BMI $\geq 85$ th and $\geq 95$ th percentiles were used to define overweight and obesity according to the 2000 CDC growth charts. The prevalence of 'high normal' and 'elevated' BP was assessed by comparing the subjects' SBP and DBP with age-, gender-, and height-specific 90th and 95th percentile reference values from the US National High Blood Pressure Education Program. Metabolic syndrome was defined using International Diabetes Federation guidelines.

Results A high proportion of Emirati adolescents (21\%) were obese compared to their non-local counterparts (16\%). Off the study adolescents $6 \%$ had elevated blood pressure. A high proportion $(19.1 \%)$ of obese children had elevated blood pressure compared to those who were overweight $(4.8 \%)$ and normal (2.1\%). Prevalence of metabolic syndrome was high (42\%) among obese compared to their counterparts with overweight (14\%) and normal weight (5\%).

Conclusion The present findings emphasise the importance of the prevention of obesity in order to prevent future cardiovascular related problem such as hypertension.

\section{PO-0083 RELATIONSHIP BETWEEN 25 HYDROXY VITAMIN D AND OBESITY IN 2-7 YEARS OLD CHILDREN REFERRED TO A PAEDIATRIC HOSPITAL IN IRAN}

S Mohammadian, R Mortezazadeh, H Zaeri, M Vakili. Pediatrics, Child and Neonatal Research Center GOUMS, Gorgan, Iran

\subsection{6/archdischild-2014-307384.753}

Background In observational studies vitamin D was one of the factors associated with obesity.

Aims Determine the association between BMI and serum level of vit $\mathrm{D}$ in children from

Taleghani hospital as outpatient in Iran.

Design This was a cross-sectional observational study on 215 children, 2 to 7 years old referred to hospital in winter 2013 .

Methods and material In cross sectional study, it was measured weight, height, waist circumference with identical instrument, Also determined BMI, Vitamin D level was performed on ELISA method.

Statistical analysis Vitamin D levels less than $20 \mathrm{nmol} / \mathrm{L}$ was considered as deficiency, $20-30 \mathrm{nmol} \backslash \mathrm{L}$ as inadequate and equal to or greater than $30 \mathrm{nmol} \backslash \mathrm{L}$ as sufficient.it was applied t-test, ANOVA, Pearson correlation coefficient at the significant level of 0.05 , data were analysed by SPSS.

Results 125 children were male and the rest were females 184 children had vitamin D deficiency and only 31 cases had adequate level. The prevalence of obesity and overweight was 
$27 \%$, considering vitamin D status it was not significant. However, the linear relationship was between waist circumference and serum vitamin $\mathrm{D}(\mathrm{p}<0.01)$. The mean and standard deviation of vitamin $\mathrm{D}$ serum in girls and boys were 22/76 \pm 11/62 and $23 / 46 \pm 9 / 30 \mathrm{nmol} / \mathrm{L}$ and this difference was not significant.

Conclusions There was high prevalence of vit D deficiency in 2 to 7 years old. There was no significant relationship between $\mathrm{BMI}$ and vit D, but it was recorded in waist circumference with vitamin D level.

\section{PO-0084 VARIOUS PATHOGENETIC VARIANTS PROGRESSION OF OBESITY IN ADOLESCENTS}

'G Maskova, 'NL Chernaya, ${ }^{2} \mathrm{EYU}$ Nagornova, 'SA Baurova. 'Polyclinic Pediatrics Department, Yaroslavl Medical Academy, Yaroslav, Russia; ${ }^{2}$ Functional Diagnostics Department, Regional Children's Clinical Hospital, Yaroslav, Russia

\subsection{6/archdischild-2014-307384.754}

Methods We have conducted clinical, functional and laboratory examination of 104 adolescents 11-18 years with a primary abdominal obesity. The body mass index (BMI) of all children exceeded 95 percentile. It was studied the reaction of the brachial artery in the process of conducting endothelial test with reactive hyperemia and calculated of percentage flow-mediated dilation (\%FMD).

Results In 66\% $(\mathrm{n}=67)$ cases in adolescents identified endothelial dysfunction on the basis of positive endothelial samples (FMD <10\%).

A further analysis was performed among children with dysfunction of endothelium of the brachial artery. The children were divided in to 2 groups: group A $(\mathrm{n}=31)$ - children with stable essential hypertension;group B $(\mathrm{n}=36)$ - children with labile hypertension or normal blood pressure.

In adolescents of the group A with a moderate increase in the percentage content of fat mass $(M=31.4 \pm 4.7 \%)$ disorders in the blood are recorded: hyperglycemia $-16,6 \%$, hypercholesterolemia in $4 \%$, hyperinsulinemia in $27 \%$, with the development of insulin resistance in $17 \%$. Children of group B were characterised by significantly more pronounced disorders in the blood. They registered with a higher percentage of body fat in the body $(\mathrm{M}=39.45 \pm 4.4 \%)$. Hyperglycemia was reported in 33\% (p $=0.04)$, hypercholesterolemia at $33 \%(\mathrm{p}=0.04)$, hyperinsulinemia at $45 \%(\mathrm{p}=0.041)$ with the development of insulin resistance in $30 \%(\mathrm{p}=0.042)$.

Conclusions The analysis of groups allows defining a primary factor that causes dysfunction of endothelium at obesity (high blood pressure or hyperinsulinemia), as well as to suggest which of the pathogenetic variants may further progress obesity: essential hypertension or diabetes type 2 .

\section{PO-0085 ASSESSMENT OF RISK OF OBESITY IN CHILDREN AT BIRTH IN THE RUSSIAN FEDERATION}

G Maskova, NL Chernaya, IV Eltcova. Polyclinic Pediatrics Department, State Medical Academy, Yaroslav, Russia

\subsection{6/archdischild-2014-307384.755}

Purpose We evaluated the risk of obesity in newborns in a large industrial city in the Russian Federation, were born in 2014.
Methods We conducted a survey of 100 mothers of infants with an adapted original questionnaire «Predicted probability of childhood obesity from traditional risk factor». The questionnaire included a value of body weight at birth, the factor of maternal smoking during pregnancy, body mass index (BMI) of the parents, the professional status of the mother and the number of family members living together. We calculated the risk of obesity in children using the online calculator «files-good.ibl.fr/childhood-obesity». The risk of obesity is carried out in compliance with recommendations (Morandi et al. 2012).

Results We found that $14 \%$ of newborns at high risk (risk > $50 \%$ ), and $28 \%$ - medium risk (risk of 25-50\%) in the development of obesity. Thus, $42 \%$ of infants in need of an obesity prevention. The statistical analysis (STATISTICA, Ver.10, Correlations Spearman, $\mathrm{p} \leq 0.05$ ) allowed us to establish a stable relationship the risk of developing obesity with birth weight $(\mathrm{r}=0.43)$ and maternal BMI by the end of pregnancy $(\mathrm{r}=$ 0.37), indicating the importance of antenatal metabolic programming in its development.

In our research we didn't receive communication of risk of development of obesity with smoking of mother during pregnancy.

Conclusion In Russia of $42 \%$ of newborn children have high probability to create obesity and need prevention. From social factors the role of high material security of a family and insufficient educational level of mother is proved.

\section{PO-0086 CLINICAL UTILITY OF THE CONJUGATED LINOLEIC ACID AS ADYUVANT ON OVERWEIGHT AND OBESITY TREATMENT IN CHILD AND ADOLESCENT}

A Perea, G Lopez, C Santamaria, M Ynga, A Lara, M Padron. Obesity Clinic, Instituto Nacional de Pediatría, Mexico City, Mexico

10.1136/archdischild-2014-307384.756

Background and aims Obesity as a universal public health problem requires precise measuresto limit its impact on the population. Antiobesity drugs have been used in adults andadolescents. The use of nutritional aids isnoted in the literature as a treatment option for obesity. Conjugated linoleic acid (CLA) has beenused in general population including children, causing a reduction in weight, body mass index (BMI) and waist circumference (WC) after administration for 12 to 104 weeks. The objective was to determine theusefulness of CLA added to the lifestyle intervention, reflected insomatometric parameters in a group of children and adolescents with obesity.

Methods 21 children and adolescents with overweight andobesity, used CLA during 12 weeks and then only lifestyle up to 32 weeks. They were cited every 4 weeks to measurement of weight, height, BMI, WC, waistheight index (WHI) and blood pressure.

Results All patients were monitoring 32 weeks, 14 attended $100 \%$ of the appointments. There was a continuous decrease of the WHI and BMI even afterCLA was suspended, attributing this effect to continued lifestyle intervention, despite a BMI rebound at week 16.

Conclusions The use of CLA may be useful as adjuvant during lifestyleintervention (diet and physical activity) in obese children and adolescents.

PO-0087 WITHDRAWN 